\title{
Effects of antibiotics and oil on microbial profiles and fermentation in mixed cultures of ruminal microorganisms
}

\author{
M. C. Johnson, ${ }^{*}$ A. A. Devine, $†$ J. C. Ellis, $\ddagger$ A. M. Grunden, $†$ and V. Fellner* \\ *Department of Animal Science, and \\ †Department of Microbiology, North Carolina State University, Raleigh 27695 \\ łln Silico LLC, Fuquay-Varina, NC 27526
}

\section{ABSTRACT}

Ionophores and supplemental fat are fed to lactating cows to improve feed efficiency. Their effect on rumen fermentation is similar, but less is known about their impact on rumen microbes. The objective of this study was to determine the effects of monensin $(\mathrm{M})$, bacitracin (B), and soybean oil (O) on microbial populations. Mixed cultures of rumen microbes were incubated in 5 dual-flow continuous fermentors and fed $13.8 \mathrm{~g}$ of alfalfa hay pellets daily (DM basis) for $16 \mathrm{~d}$. All fermentors were allowed to stabilize for $4 \mathrm{~d}$. From d 5 to 10 , two fermentors received $\mathrm{O}$ ( $5 \%$ of $\operatorname{diet} \mathrm{DM})$, one fermentor received M $(22 \mathrm{mg} / \mathrm{kg})$, and one received B $(22 \mathrm{mg} / \mathrm{kg})$. From d 11 to 16 , the 2 fermentors receiving $\mathrm{O}$ also received either $\mathrm{M}(\mathrm{OM})$ or $\mathrm{B}(\mathrm{OB})$ and $\mathrm{O}$ was included in the fermentors receiving $\mathrm{M}(\mathrm{MO})$ and $\mathrm{B}$ (BO). One fermentor served as the control and received $100 \%$ alfalfa pellets throughout the experiment. Each run was replicated 3 times. Samples were taken at $2 \mathrm{~h}$ after the morning feeding on d 4, 10, and 16 and were analyzed for bacterial populations using terminal restriction fragment length polymorphism. Volatile fatty acid concentration, methane production, and $\mathrm{pH}$ in the control cultures were not affected by time and remained similar during the entire experiment. The $\mathrm{M}$ and $\mathrm{O}$ treatments reduced molar concentration of acetate, increased concentration of propionate, and decreased methane production. Bacitracin did not alter acetate or propionate concentration, but reduced methane production. All 3 treatments $(\mathrm{M}, \mathrm{B}$, and $\mathrm{O})$ altered the fragment patterns of microbial profiles. In contrast, treatments $\mathrm{MO}, \mathrm{OM}, \mathrm{BO}$, and $\mathrm{OB}$ had little effect on culture fermentation despite differences in the patterns of microbial fragments. The terminal restriction fragment length polymorphism data suggest that microbial adaptation to the in vitro system in the control fermentor occurred within $4 \mathrm{~d}$.

Received October 27, 2008.

Accepted June 2, 2009.

${ }^{1}$ Corresponding author: Vivek_Fellner@ncsu.edu
Key words: ionophore, soybean oil, rumen microbial diversity, continuous culture

\section{INTRODUCTION}

Cows in peak lactation are typically fed supplemental fat and ionophores to help meet their nutrient requirements. Individually, these additives improve the efficiency of feed conversion. Fat can increase the energy density of the diet without reducing fiber (Palmquist and Jenkins, 1980). Ionophores improve the feed:gain ratio (Pressman, 1976) by altering rumen fermentation and the proportions of VFA. In the United States, monensin has been fed to beef cattle since 1975 and to lactating dairy cattle since 2005, and is the most commonly used ionophore in ruminant diets. Both fat and monensin have been shown to decrease the acetate:propionate $(\mathbf{A}: \mathbf{P})$ ratio and reduce methane production (Russell and Strobel, 1989; Jenkins, 1993) by altering microbial populations within the rumen (Van Nevel and Demeyer, 1995; Sauer et al., 1998; Jenkins et al., 2003). Supplemental fat may physically coat fiber or bind to microbes, thus inhibiting specific microorganisms and changing the populations in the rumen (Palmquist and Jenkins, 1980). Monensin is an antiporter that disrupts the ion gradients in microbial cells, causing a depletion of the ATP supply, thus inhibiting growth (Russell, 1987). Monensin is most active against gram-positive bacteria, which lack a protective outer membrane, whereas gram-negative bacteria, which have outer membranes, are less susceptible to the antibiotic (Russell, 1987). Bacitracin, a less commonly fed antibiotic, is a cyclic peptide that can also be fed as a growth promoter (Butaye et al., 2003) and has similar effects as monensin (Russell and Strobel, 1988). It also acts on gram-positive bacteria (Russell and Strobel, 1988), but unlike monensin, bacitracin inhibits cell wall synthesis (Siewert and Strominger, 1967), thereby affecting cell growth.

When fed alone, monensin and oil improve the efficiency of fermentation, but their effects do not seem to be additive (Clary et al., 1993; Zinn and Borques, 1993). Some data suggest that the inhibition of gram- 
positive bacteria alone by monensin may not fully explain the response. Gram-positive bacteria are known to hydrogenate the fatty acid C18:2 to C18:1, yet this step can occur during monensin supplementation (Fellner et al., 1997; Sauer et al., 1998). Lipolytic and hydrogenating bacteria are reported to be mostly gram negative, but monensin has been shown to inhibit lipolysis. It is therefore possible that in addition to inhibiting grampositive bacteria, monensin may alter the metabolism of gram-negative bacteria (Van Nevel and Demeyer, 1995).

Rumen microbes require fatty acids to incorporate into their cell membranes (Demeyer et al., 1978). In the presence of excess dietary fatty acids, incorporation can exceed synthesis (Bauchart et al., 1990). Fat supplementation has been shown to alter the microbial lipid profile and subsequent microbial function (Kucuk et al., 2008). The mode of ionophore function is dependent on the fluidity of the membrane lipid bilayer (Sankaram et al., 1987), and altering the lipid composition can lower membrane fluidity and decrease the rate of transport of the ionophore across the membrane (Kolber and Haynes, 1981). Monensin and bacitracin have similar effects, but their mechanism of action is different. This study was conducted to identify the effect of ionophores and soybean oil on fermentation. A second objective was to determine whether the sequence in which microbes received ionophores and soybean oil altered the fermentation pattern and microbial populations in mixed cultures of ruminal organisms.

\section{MATERIALS AND METHODS}

\section{Fermentor Conditions}

Whole ruminal contents were obtained approximately $2 \mathrm{~h}$ after the morning feeding from a ruminally fistulated cow fed a predominantly forage diet. Contents were transported to the laboratory in a prewarmed vacuum container, where they were filtered through double-layered cheesecloth. Before the addition of ruminal inoculum, the fermentors (total volume of $1 \mathrm{~L}$ ) were purged with $\mathrm{CO}_{2}$ to displace any $\mathrm{O}_{2}$ and heated to $39^{\circ} \mathrm{C}$, and the saliva line was primed. Approximately $700 \mathrm{~mL}$ of the strained ruminal fluid was transferred into each of the 5 fermentors. Culture vessels used in this study were an all-glass, closed system type with a continuous independent flow of liquid and particulate matter. Air leakage into the fermentor is avoided by 1 ) rubber seals and 2) a continuous flow of $\mathrm{CO}_{2}(20 \mathrm{~mL} /$ min), which maintains anaerobic conditions as well as a positive internal pressure. Throughout the trial, the water bath maintained the fermentor temperature at $39^{\circ} \mathrm{C}, \mathrm{CO}_{2}$ flow was set at a constant rate of $20.0 \mathrm{~mL} /$ min, and artificial saliva was delivered with a precision pump at $0.73 \mathrm{~mL} / \mathrm{min}$, which resulted in a fractional liquid dilution rate of $6.8 \% / \mathrm{h}$. Fermentors were stirred continuously at $10 \mathrm{rpm}$. Fermentor design and operating conditions have been reported previously (Fellner et al., 1997; Jenkins et al., 2003).

\section{Diets and Additives}

The feed consisted of alfalfa hay pellets purchased from a local feed store. Monensin and bacitracin were purchased from Sigma Chemical Co. (St. Louis, MO), and soybean oil (Wesson brand) was purchased at a local grocery store. One kilogram of alfalfa hay per treatment was placed in a blender and $22 \mathrm{mg}$ of the respective antibiotic was gradually added and mixed thoroughly to ensure complete distribution of the antibiotic. Alfalfa pellets (13.8 g of $\mathrm{DM} / \mathrm{d})$ were fed in equal portions at 0700 and $1400 \mathrm{~h}$ to all fermentors during the experiment. Soybean oil was added $(345 \mu \mathrm{L} /$ feeding) directly into the liquid phase of the culture contents. Total fatty acid content of soybean oil was $88.1 \%$ and consisted predominantly of C18:2 (55\%) and cis $\mathrm{C} 18: 1$ (22.5\%).

From d 1 to 4 (stabilization period), all fermentors received only alfalfa pellets. From d 5 to 10, two fermentors received soybean oil $(\mathbf{O} ; 5 \%$ of diet DM), one fermentor received monensin (M; $22 \mathrm{mg} / \mathrm{kg}$ ), and one received bacitracin $(\mathbf{B} ; 22 \mathrm{mg} / \mathrm{kg})$. From d 11 to $16, \mathrm{M}$ was included in one of the $\mathrm{O}$ treatments $(\mathbf{O M})$ and $\mathrm{B}$ was included in the other $\mathrm{O}$ treatment $(\mathbf{O B})$. During this same time, $\mathrm{O}$ was included in the $\mathrm{M}(\mathbf{M O})$ and B (BO) treatments. Each run consisted of a total of 5 fermentors. One fermentor served as the control and received $100 \%$ alfalfa pellets throughout the experiment. Each run was replicated 3 times.

\section{Sample Collection and Fermentation Measurements}

Samples for bacterial quantification were collected on d 4, 5, 9, 10, 11, 15, and 16. Samples for VFA, longchain fatty acids, ammonia, and terminal restriction fragment length polymorphism (T-RFLP) analyses were obtained at $2 \mathrm{~h}$ after the morning feeding on $\mathrm{d}$ 4,10 , and 16 . Culture contents were mixed thoroughly before sampling to obtain a homogeneous sample. Methane and $\mathrm{pH}$ were recorded daily $2 \mathrm{~h}$ after feeding. Methane gas measurements were obtained by filling a gastight syringe (Hamilton Co., Reno, NV) with $10 \mu \mathrm{L}$ of fermentor headspace gas. The fermentor headspace samples were analyzed directly by gas chromatography (model CP-3380; Varian, Walnut Creek, CA), and daily methane output $(\mathrm{mmol} / \mathrm{d})$ was calculated using the following equation: methane concentration in fermentor 
headspace $(\mathrm{mmol} / \mathrm{mL}) \times \mathrm{CO}_{2}$ gas flow through the fermentor headspace $(20 \mathrm{~mL} / \mathrm{min}) \times 60 \mathrm{~min} \times 24 \mathrm{~h}$. Digestibility was calculated as the grams of feed used for VFA plus methane per $100 \mathrm{~g}$ of dry feed added to the fermentors each day. On d 4, 10, and 16 at $0900 \mathrm{~h}$, two 1-mL samples were obtained for VFA and ammonia analysis. Samples for ammonia were stored immediately at $-70^{\circ} \mathrm{C}$. The VFA samples were immediately processed by suspending them in metaphosphoric acid and were centrifuged (model Micromax; International Equipment Co., Needham Heights, MA) at 21,000 $\times g$ for $10 \mathrm{~min}$ at $4^{\circ} \mathrm{C}$. Samples were then stored at $-70^{\circ} \mathrm{C}$ until subsequent analysis. Ammonia was analyzed by a colorimetric procedure (Beecher and Whitten, 1970) and the VFA were analyzed by GLC (model CP-3380; Varian) using a fused-silica capillary column, $30 \mathrm{~m} \times$ $0.25 \mathrm{~mm}$ with $0.25-\mu \mathrm{m}$ film thickness (Nukol; Supelco Inc., Bellefonte, PA) according to the method of Fellner et al. (1997).

\section{Bacterial Counts}

Bacterial counts were obtained for the fresh inoculum and for the culture contents $2 \mathrm{~h}$ after feeding on $\mathrm{d} 4$, $9,10,15$, and 16. Bacterial counts were done with a phase-contrast microscope (Nikon Type 119; Nikon, Tokyo, Japan) using a hemocytometer (Hausser Scientific, Horsham, PA) after diluting the sample with Luria Bertani broth.

\section{T-RFLP Analysis}

The T-RFLP analysis was similar to that reported earlier (Liu et al., 1997; Kent et al., 2003) with some modifications. A 10-mL sample was taken from each fermentor on d 4, 10, and 16. Each sample was obtained $2 \mathrm{~h}$ after the morning feeding and stored at $-70^{\circ} \mathrm{C}$ until genomic DNA (gDNA) was isolated. Samples were thawed, one 250-mg subsample was taken, and DNA was extracted using a PowerSoil DNA isolation kit (MoBio Laboratories Inc., Solana Beach, CA). The 16S ribosomal DNA (rDNA) was amplified from the isolated gDNA samples using the bacterial-specific $16 \mathrm{~S}$ rDNA primers $8 \mathrm{~F}$ (5'-AGAGTTTGATC(A/C)TGGCTCAG-3') and 1492R (5'-GGTTACCTTGTTACGACTT- $3^{\prime}$ ). The forward primer for the PCR reaction was labeled on the $5^{\prime}$ end with a hexamide fluor marker to allow the terminal fragment to be tracked. Each gDNA sample was amplified in 2 PCR reactions, with each reaction $(100 \mu \mathrm{L})$ containing $10 \mu \mathrm{L}$ of $10 \times$ buffer, $0.8 \mu \mathrm{L}$ of deoxynucleotide $5^{\prime}$-triphosphate $(40 \mathrm{mmol})$, $0.5 \mu \mathrm{L}(100 \mathrm{pmol} / \mu \mathrm{L})$ of fluorescently labeled forward primer, $0.5 \mu \mathrm{L}(100 \mathrm{pmol} / \mu \mathrm{L})$ of reverse primer, $0.5 \mu \mathrm{L}$ of Taq polymerase (2.5 U total; Qiagen Inc., Valencia,
CA), $86.7 \mu \mathrm{L}$ of PCR grade water, and $1 \mu \mathrm{L}$ of gDNA. The PCR was performed using an iCycler (Bio-Rad Laboratories, Hercules, CA) and a thermal profile of an initial 3-min denaturing step at $94^{\circ} \mathrm{C}$, followed by 25 cycles of a $94^{\circ} \mathrm{C}$ denaturing step for $1 \mathrm{~min}, 50^{\circ} \mathrm{C}$ annealing step for $1 \mathrm{~min}$, and $72^{\circ} \mathrm{C}$ extension step for $2 \mathrm{~min}$, with a final $7 \mathrm{~min}$ of extension at $72^{\circ} \mathrm{C}$. One microliter of each PCR reaction was run on a $1 \%$ agarose gel at $120 \mathrm{~V}$ for $60 \mathrm{~min}$ to verify amplification of bacterial $16 \mathrm{~S}$ rDNA sequences and confirm that the reactions were not contaminated.

The 2 PCR reactions amplifying each DNA sample were pooled and purified using the UltraClean PCR Clean-up Kit (MoBio Laboratories Inc.), and $1 \mu \mathrm{L}$ of each purified PCR reaction was run on a $1 \%$ agarose gel at $120 \mathrm{~V}$ for $60 \mathrm{~min}$ for visualization. The PCR products were then aliquoted and digested in 3 separate reactions. Each of 3 tubes contained $15 \mu \mathrm{L}$ of the purified PCR reaction, $74 \mu \mathrm{L}$ of PCR grade water, $1 \mu \mathrm{L}$ of 1 of 3 enzymes (RsaI, MspI, or HhaI), and $10 \mu \mathrm{L}$ of its corresponding buffer. The HhaI reaction required $1 \mu \mathrm{L}$ of $100 \times$ BSA and contained $73 \mu \mathrm{L}$ of water. All enzymes were purchased from New England BioLabs (Beverly, MA). The digestion reactions were incubated overnight at $37^{\circ} \mathrm{C}$ and heat inactivated by immersing in a $60^{\circ} \mathrm{C}$ water bath for $20 \mathrm{~min}$. The digested DNA was purified using the QIAquick Nucleotide Removal Kit (Qiagen Inc.) and was eluted into $50 \mu \mathrm{L}$ of heated PCR grade water. Ten microliters of each purified sample was run on a $1 \%$ agarose gel at $120 \mathrm{~V}$ for $60 \mathrm{~min}$. Thirty microliters of each sample was placed in $1.5-\mathrm{mL}$ microcentrifuge tubes, wrapped in Parafilm, and stored at $-80^{\circ} \mathrm{C}$ until shipped to the Genomic Technology Support Facility at Michigan State University (East Lansing) for analysis on an Applied Biosystems Prism 3100 Gene Analyzer (Applied Biosystems, Foster City, $\mathrm{CA}$ ). The fragment data files were filtered so only information associated with the tagged PCR products remained. The resulting fragment patterns were analyzed using the In Silico software package (In Silico LLC, Fuquay-Varina, NC).

\section{Analyses of T-RFLP Data}

In Silico has built-in single-value diversity indices for the T-RFLP analysis. These indices include the Shannon-Weaver index $\left(\mathbf{H}^{\prime}\right)$, Simpson diversity (reported as 1-D), the reciprocal Simpson (1/D), and evenness $(\mathbf{E})$. The diversity equations used in In Silico have been described previously (Tajima et al., 1999; Blackwood et al., 2007). For calculation of the indices, the T-RFLP analysis peak area was used as the amount measurement and its relative abundance was measured by dividing individual peaks by the total fluorescence 


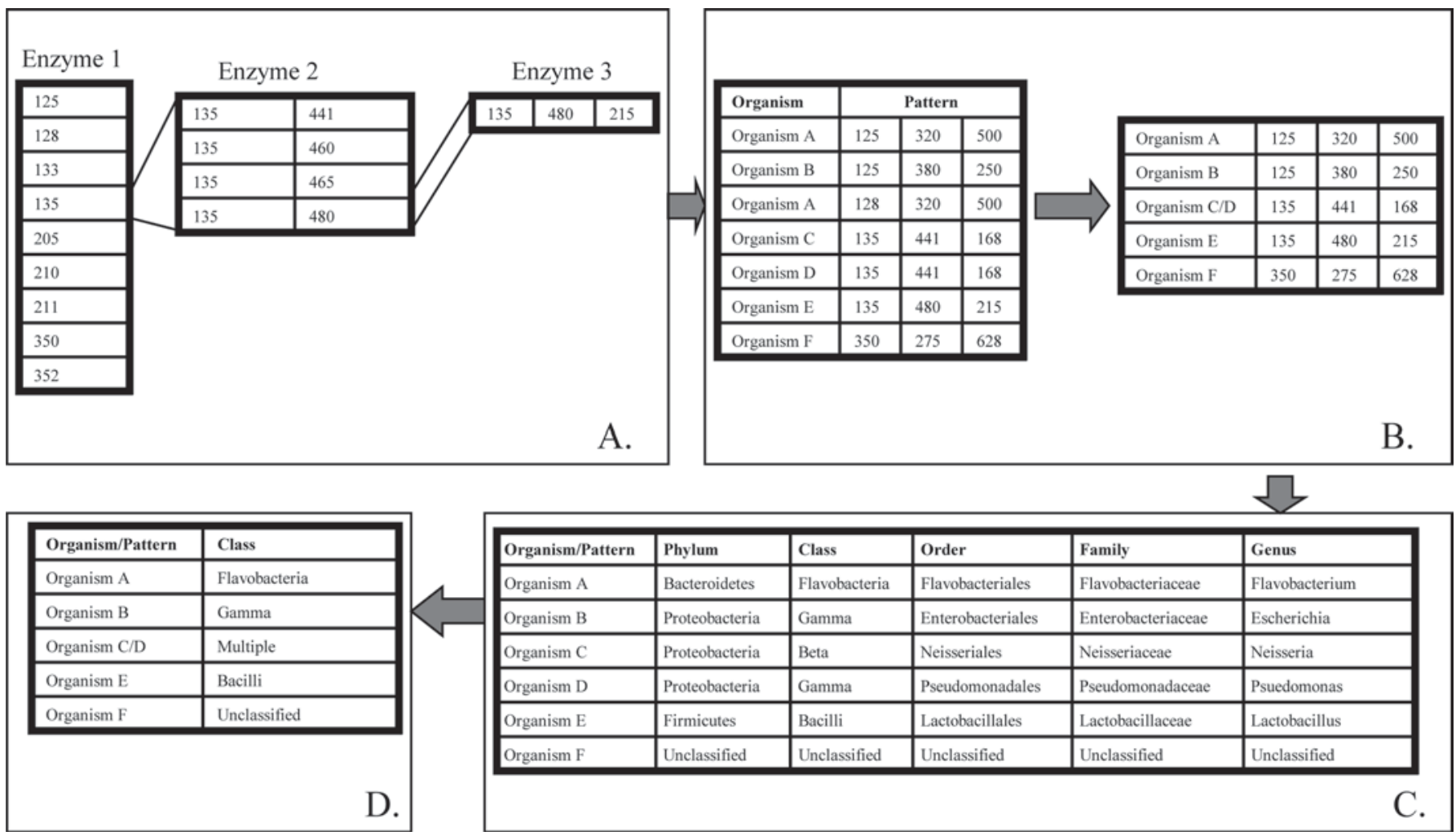

Figure 1. A flow diagram describing the In Silico software (In Silico LLC, Fuquay-Varina, NC) process used to generate community profiles. A) Fragments generated from separate restriction digests are sequentially matched to patterns found in the In Silico database. B) Matched patterns are compressed by removing extraneous patterns that belong to a single organism, as in organism A, or by combining multiple organisms that have the same pattern, as in organism C and organism D. C) Patterns are then matched to phylogenetic information in the In Silico software and reported at 5 different levels. D) In the final output of the In Silico software package, organisms are identified by class. Note that the pattern belonging to organisms $\mathrm{C}$ and $\mathrm{D}$ is identified as "multiple" because the 2 organisms belong to different classes. Organism $\mathrm{F}$ is defined as unclassified because no phylogenetic information is available for the pattern.

of the sample. The results for each diversity measure are representative of the number of fragments in each fermentor.

\section{Statistical Analysis of Fermentation Data}

Fermentation data from the last $2 \mathrm{~d}$ of each treatment period were analyzed according to a randomized complete block design using the MIXED procedure (SAS Institute, Cary, NC). From d 5 to 10, an average of the 2 fermentors receiving $\mathrm{O}$ was used in the analysis. Sources of variations in the model included additive, sequence, and the additive $\times$ sequence interaction tested against residual error. Day and run were included as the repeated and random variables, respectively. Significance is reported at $P<0.05$.

\section{RESULTS AND DISCUSSION}

\section{T-RFLP Data}

Pattern detection and pattern identification were carried out using the In Silico software package (In Silico LLC). Fragments were sequentially matched to patterns as described previously (Kent et al., 2003; Figure 1A). A compression utility was used to remove multiple matches to the same organism and to combine patterns that matched multiple organisms (Figure 1B). The final pattern set was applied to a phylogenetic sorting algorithm matching the $16 \mathrm{~S}$ rDNA genes to the phylogeny in the National Center for Biotechnology Information (NCBI) sequence database (Figure 1C).

The resulting matched fragment patterns provide information on the diversity of the populations. The percentages of fragments used by the In Silico database to assign organism identifications (matched fragments) are presented in Table 1. Although the identified patterns can be reported by In Silico at 5 different phylogenetic levels (phylum, order, class, family, and genus; Figure 1 ), the data in this study are presented at the class level because this gives information about the metabolic capacity of the microorganisms while still providing a concise graphical representation of the diversity of the populations.

The "unclassified" grouping of patterns differ from unmatched fragments because little or no phylogenetic 
Table 1. Use by In Silico of fragments generated by terminal restriction fragment length polymorphism (T-RFLP)

\begin{tabular}{lrrr}
\hline & \multicolumn{3}{c}{ Use of fragments, $^{2} \%$} \\
\cline { 2 - 4 } Treatment $^{1}$ & \multicolumn{1}{c}{ Rsal ${ }^{3}$} & \multicolumn{1}{c}{ HhaI $^{3}$} & \multicolumn{1}{c}{ Msp $^{3}$} \\
\hline C (d 4) & $94(32 / 34)$ & $97(37 / 38)$ & $100(32 / 32)$ \\
C (d 10) & $83(19 / 23)$ & $100(24 / 24)$ & $95(35 / 37)$ \\
C (d 16) & $93(14 / 15)$ & $93(13 / 14)$ & $89(24 / 27)$ \\
M (d 10) & $79(30 / 38)$ & $82(27 / 33)$ & $90(19 / 21)$ \\
B (d 10) & $90(27 / 30)$ & $95(37 / 39)$ & $98(43 / 44)$ \\
O (d 10) & $100(22 / 22)$ & $100(32 / 32)$ & $92(44 / 48)$ \\
MO (d 16) & $51(21 / 41)$ & $85(11 / 13)$ & $75(27 / 36)$ \\
OM (d 16) & $95(20 / 21)$ & $100(20 / 20)$ & $92(23 / 25)$ \\
BO (d 16) & $84(27 / 32)$ & $100(15 / 15)$ & $95(35 / 37)$ \\
OB (d 16) & $96(23 / 24)$ & $87(27 / 31)$ & $95(40 / 42)$ \\
\hline
\end{tabular}

${ }^{1}$ Treatments: $\mathrm{C}=$ control; $\mathrm{M}=$ monensin; $\mathrm{B}=$ bacitracin; $\mathrm{O}=$ oil; $\mathrm{MO}=$ monensin + oil; $\mathrm{OM}=$ oil + monensin $; \mathrm{BO}=$ bacitracin + oil; $\mathrm{OB}=$ oil + bacitracin

${ }^{2}$ Fragments used by the In Silico database (In Silico LLC, FuquayVarina, NC) to assign organism identifications. Numbers in parentheses indicate fragments used by In Silico over the total number of fragments detected in each of the restriction digests.

${ }^{3}$ Restriction enzyme used in the T-RFLP analysis.

information is deposited with their respective sequence. Unclassified sequences make up a large percentage of the data because sequences are often deposited without sufficient phylogenetic identification.

Fragment patterns in the multiple classification fit into more than one distinct phylogenetic group and consist of all the unique species from phylogenetically different groups that match a single fragment pattern.
Approximately one-half of the unique patterns in the samples across all treatments were from unclassified microorganisms and approximately one-fourth belonged to patterns with multiple phylogenies. This is consistent with previous clone library studies, which also suggest that many of the organisms in the rumen are currently uncharacterized (Tajima et al., 1999, 2000; Edwards et al., 2004).

\section{Fermentation in Control Cultures}

After the stabilization period (4 d), fermentation patterns in the control cultures remained stable. Rufener et al. (1963) also reported a normal in vitro fermentation pattern in continuous cultures for experimental periods from d 3 to 10. Methane production averaged $28 \mathrm{mmol} / \mathrm{d}$, pH was 6.0 , and ammonia averaged 24.3 $\mathrm{mg} / 100 \mathrm{~mL}$. Total VFA concentrations averaged 55.7 $\mathrm{m} M$ and individual VFA did not change; the A:P ratio remained constant at 3.8 throughout the study. Bacterial cell numbers in the control fermentors averaged $1.35 \times 10^{9}$ cells $/ \mathrm{mL}$ and did not change over time. Bacterial counts were high but were similar to those reported earlier in vivo (Thorley et al., 1968) and in continuous cultures (Rufener et al., 1963). Data on the concentrations and proportions of VFA, methanogenesis, bacterial numbers, and culture $\mathrm{pH}$ indicate that a stable fermentation was maintained in vitro from d 5 and 16 of the experimental period. Hence, fermentation data averaged across d 5 to 16 for the control were used

Table 2. The effect of additives and their sequence on VFA, methane, $\mathrm{pH}$, and ammonia in continuous cultures of mixed ruminal microbes

\begin{tabular}{|c|c|c|c|c|c|c|c|c|c|}
\hline Item & \multicolumn{4}{|c|}{ Treatment $^{1}$} & \multicolumn{4}{|c|}{ Sequence $^{2}$} & $\mathrm{SE}$ \\
\hline $\begin{array}{l}\text { Total VFA, }{ }^{3} \mathrm{~m} M \\
\text { Individual VFA, mol/100 mol }\end{array}$ & 49.8 & 49.2 & 52.8 & 48.6 & 59.8 & 60.3 & 67.9 & 63.9 & 7.17 \\
\hline Acetate $(\mathrm{A})$ & $68.1^{\mathrm{a}}$ & $60.5^{\mathrm{b}}$ & $65.3^{\mathrm{ab}}$ & $61.4^{\mathrm{b}}$ & 58.4 & 58.3 & 61.3 & 60.7 & 4.11 \\
\hline Propionate $(\mathrm{P})$ & $19.2^{\mathrm{e}}$ & $22.8^{\mathrm{f}}$ & $18.6^{\mathrm{eg}}$ & $21.4^{\mathrm{fg}}$ & 24.4 & 25.4 & 22.6 & 23.5 & 2.67 \\
\hline Butyrate & $8.3^{\mathrm{a}}$ & $10.8^{\mathrm{b}}$ & $10.8^{\mathrm{b}}$ & $11.0^{\mathrm{b}}$ & 11.2 & 10.2 & 10.5 & 10.5 & 0.96 \\
\hline $\mathrm{A}: \mathrm{P}$ & $3.6^{\mathrm{e}}$ & $2.7^{\mathrm{f}}$ & $3.6^{\mathrm{eg}}$ & $3.0^{\mathrm{fg}}$ & 2.4 & 2.5 & 3.1 & 2.7 & 0.60 \\
\hline Microbes, $10^{9} / \mathrm{mL}$ & 1.4 & 1.3 & 1.3 & 1.3 & 1.0 & 1.1 & 1.1 & 1.5 & 0.16 \\
\hline Methane, $\mathrm{mmol} / \mathrm{d}$ & $30.1^{\mathrm{e}}$ & $17.9^{\mathrm{f}}$ & $24.8^{\mathrm{g}}$ & $19.4^{\mathrm{f}}$ & 18.9 & 19.0 & 21.9 & 19.5 & 2.89 \\
\hline Culture $\mathrm{pH}$ & $6.0^{\mathrm{a}}$ & $6.2^{\mathrm{b}}$ & $6.1^{\mathrm{ab}}$ & $5.9^{\mathrm{c}}$ & $6.0^{\mathrm{x}}$ & $5.7^{\mathrm{y}}$ & 5.9 & 5.8 & 0.06 \\
\hline $\mathrm{NH}_{3}-\mathrm{N}, \mathrm{mg} / 100 \mathrm{~mL}$ & 23.8 & 22.0 & 22.0 & 22.7 & 24.6 & 23.9 & 23.4 & 24.8 & 1.63 \\
\hline DM digestibility, ${ }^{4} \%$ & 43.0 & 38.4 & 43.3 & 38.3 & 45.6 & 45.5 & 51.9 & 48.5 & 5.20 \\
\hline
\end{tabular}

${ }^{\mathrm{a}-\mathrm{c}}$ Means with different superscripts within additive differ $(P<0.01)$.

${ }^{\mathrm{e}-\mathrm{g}}$ Means with different superscripts within additive differ $(P<0.05)$.

${ }^{\mathrm{x}, \mathrm{y}}$ Means with different superscripts within sequence differ $(P<0.01)$.

${ }^{1}$ Treatments: $\mathrm{C}=$ control; $\mathrm{M}=$ monensin; $\mathrm{B}=$ bacitracin; $\mathrm{O}=$ oil.

${ }^{2}$ Sequence: $\mathrm{MO}=$ monensin + oil; $\mathrm{OM}=$ oil + monensin; $\mathrm{BO}=$ bacitracin + oil; $\mathrm{OB}=$ oil + bacitracin.

${ }^{3}$ Additive $\times$ sequence interaction $(P<0.05)$.

${ }^{4}$ Calculated as grams of feed used for VFA plus methane per $100 \mathrm{~g}$ of dry feed added to the fermentors each day. 
Actinobacteria

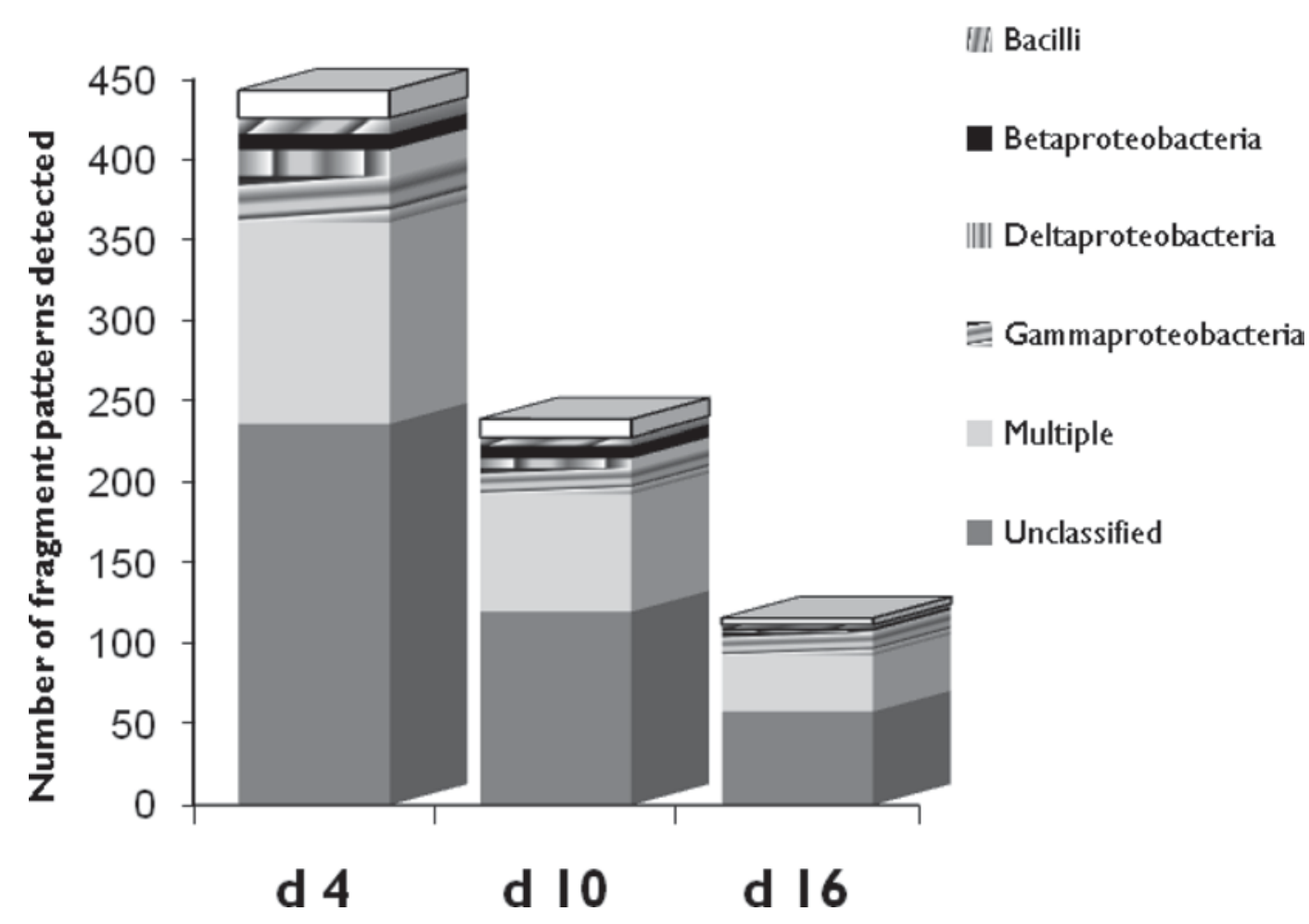

Figure 2. Class patterns identified by In Silico software (In Silico LLC, Fuquay-Varina, NC) in the control fermentor.

to compare the effect of treatments and their sequence (Table 2).

The total number of unique patterns identified in the control fermentors decreased from 472 on d 4 to 264 and 125 on d 10 and d 16, respectively (Figure 2 and Table $3)$. The decline in detectable unique patterns suggests that the overall microbial diversity in the fermentors decreased over the 16- $\mathrm{d}$ experimental period (Ziemer et al., 2000). In the control fermentor, the $\mathrm{H}^{\prime}, 1-\mathrm{D}$, and $1 / \mathrm{D}$ values all decreased over time (Table 4 ). However, the $\mathrm{E}$ value increased during that same period. The $\mathrm{H}^{\prime}$, $1-\mathrm{D}$, and $1 / \mathrm{D}$ values are based on the number of fragments detected for each time point; hence, the decrease is consistent with the decrease in fragment numbers during the corresponding period (Table 1). The E value represents the uniformity of fluorescence of the fragments; hence, in the control, although the number of fragments decreased, the proportion of the total fluorescence each fragment contributed was more uniform at d 16 compared with d 4 .

The fragment patterns belonging to 11 important rumen genera identified in the control fermentor are presented in Figure 3 and Table 5. Unique patterns belong to a single genus, and the "multiple" category includes fragment patterns belonging to multiple genera. The multiple and unclassified fragment patterns were searched for sequences in the NCBI database that contained the word "rumen" in the name of the pattern, and these results are shown in Figure 4. Although phylogenetic information is not known, it is possible to determine which fragment patterns belong to microorganisms sampled from the rumen. The key word "rumen" appeared in the unclassified division as an uncultured or unidentified rumen bacterium, and it was found in the multiple category along with other bacteria with more specific identifications.

These data indicate that microbes adapted to the continuous cultures within $4 \mathrm{~d}$. Bacterial cell counts remained unaffected during d 5 to 16 of the experimental period; however, microbial diversity declined, which was not reflected in the fermentation pattern.

\section{Effect of Treatments}

Total VFA concentrations were not affected by treatment and averaged $49.8 \mathrm{mM}$ for the control and 49.2, 52.8 , and $48.6 \mathrm{mM}$ for the $\mathrm{M}, \mathrm{B}$, and $\mathrm{O}$ treatments, respectively (Table 2 ). There was a treatment $\times$ sequence 
Table 3. Effect of treatment on the number of patterns identified by $\mathrm{In}_{\text {Silico }}{ }^{1}$ at the class level ${ }^{2}$

\begin{tabular}{|c|c|c|c|c|c|c|c|c|c|c|}
\hline Class & $\frac{\text { Day } 4}{\mathrm{C}}$ & \multicolumn{4}{|c|}{ Day 10} & \multicolumn{5}{|c|}{ Day 16} \\
\hline Acidobacteria & 1 & 0 & 0 & 1 & 0 & 0 & 1 & 0 & 1 & 0 \\
\hline Actinobacteridae & 4 & 6 & 2 & 9 & 5 & 3 & 1 & 0 & 3 & 0 \\
\hline Alpha-proteobacteria & 3 & 1 & 1 & 6 & 3 & 0 & 1 & 2 & 0 & 1 \\
\hline Bacilli & 10 & 5 & 7 & 13 & 12 & 2 & 8 & 4 & 2 & 12 \\
\hline Chlorobia & 0 & 0 & 0 & 0 & 0 & 0 & 0 & 0 & 1 & 0 \\
\hline Chloroflexi & 0 & 0 & 1 & 0 & 0 & 0 & 0 & 1 & 0 & 0 \\
\hline Clostridia & 3 & 1 & 1 & 6 & 5 & 1 & 5 & 2 & 1 & 8 \\
\hline Deferribacteres & 0 & 0 & 1 & 0 & 0 & 0 & 1 & 1 & 0 & 1 \\
\hline Delta-proteobacteria & 16 & 6 & 10 & 11 & 10 & 1 & 1 & 9 & 2 & 7 \\
\hline Epsilon-proteobacteria & 6 & 9 & 1 & 6 & 9 & 3 & 2 & 1 & 8 & 6 \\
\hline Flavobacteria & 4 & 1 & 0 & 1 & 3 & 1 & 0 & 0 & 2 & 0 \\
\hline Sphingobacteria & 3 & 2 & 1 & 4 & 1 & 0 & 0 & 2 & 1 & 1 \\
\hline Unclassified & 236 & 120 & 82 & 272 & 247 & 58 & 44 & 113 & 94 & 168 \\
\hline Verrucomicrobiae & 2 & 0 & 0 & 2 & 0 & 0 & 0 & 0 & 0 & 0 \\
\hline Total number of patterns & 472 & 264 & 177 & 612 & 473 & 125 & 88 & 216 & 197 & 346 \\
\hline
\end{tabular}

${ }^{1}$ In Silico software (In Silico LLC, Fuquay-Varina, NC).

${ }^{2}$ Treatments: $\mathrm{C}=$ control; $\mathrm{M}=$ monensin; $\mathrm{B}=$ bacitracin; $\mathrm{O}=$ oil; $\mathrm{MO}=$ monensin + oil $; \mathrm{OM}=$ oil + monensin; $\mathrm{BO}=$ bacitracin + oil; $\mathrm{OB}$ $=$ oil + bacitracin.

interaction for total VFA concentrations; the addition of $\mathrm{B}$ or $\mathrm{O}$ alone had no effect, but $\mathrm{BO}$ increased concentrations of total VFA $(P<0.05)$.

As expected, both $\mathrm{M}$ and $\mathrm{O}$ decreased the molar percentages of acetate $(P<0.01)$ and increased those of propionate $(P<0.05)$ compared with the control, which also decreased the A:P ratio $(P<0.05)$; B had no effect on concentrations of acetate and propionate $(P>0.10)$. Butyrate $(P<0.01)$ and valerate $(P<$ 0.01 ) increased with $\mathrm{M}, \mathrm{B}$, and $\mathrm{O}$ compared with the control; $\mathrm{M}$ and $\mathrm{O}$ also increased isovalerate $(P<0.05)$, whereas B had no effect.
Methane production decreased $(P<0.05)$ with $\mathrm{M}$, $\mathrm{B}$, and $\mathrm{O}$ when compared with the control (Table 2). The decrease was greatest with $\mathrm{M}$ and $\mathrm{O}$ (40.5 and $35.5 \%$, respectively) and less with B (17.6\%). Culture $\mathrm{pH}$ was greater $(P<0.01)$ with $\mathrm{M}$ and $\mathrm{B}(6.2$ and 6.1 , respectively) when compared with the control (6.0); the addition of $\mathrm{O}$ resulted in a lower $\mathrm{pH}$ (5.9) compared with the control $(P<0.01)$. Treatments had no effect $(P>0.10)$ on cell numbers or ammonia concentration.

Compared with the control (264), the total number of unique fragment patterns (d 10) was numerically lower with $\mathrm{M}$ (177), but was greater with $\mathrm{O}$ (473) and

Table 4. Diversity indices for the terminal restriction fragment length polymorphism (T-RFLP) fragment data

\begin{tabular}{lcccc}
\hline Treatment $^{1}$ & $\begin{array}{c}\text { Shannon-Weaver } \\
\text { index (H') }\end{array}$ & $\begin{array}{c}\text { Simpson } \\
\text { diversity (1-D) }\end{array}$ & $\begin{array}{c}\text { Reciprocal } \\
\text { Simpson (1/D) }\end{array}$ & $\begin{array}{c}\text { Evenness } \\
(\mathrm{E})\end{array}$ \\
\hline C (d 4) & 4.046 & 0.971 & 34.817 & 0.871 \\
C (d 10) & 3.950 & 0.971 & 35.024 & 0.891 \\
C (d 16) & 3.696 & 0.967 & 30.202 & 0.918 \\
M (d 10) & 3.369 & 0.910 & 11.087 & 0.745 \\
B (d 10) & 4.154 & 0.975 & 40.198 & 0.879 \\
O (d 10) & 4.157 & 0.977 & 42.735 & 0.899 \\
MO (d 16) & 3.817 & 0.956 & 24.213 & 0.848 \\
OM (d 16) & 3.753 & 0.966 & 29.416 & 0.895 \\
BO (d 16) & 3.962 & 0.971 & 34.424 & 0.894 \\
OB (d 16) & 3.809 & 0.955 & 22.035 & 0.833 \\
\hline
\end{tabular}

${ }^{1}$ Treatments: $\mathrm{C}=$ control; $\mathrm{M}=$ monensin; $\mathrm{B}=$ bacitracin; $\mathrm{O}=$ oil; $\mathrm{MO}=$ monensin + oil; $\mathrm{OM}=$ oil + monensin; $\mathrm{BO}=$ bacitracin + oil; $\mathrm{OB}=$ oil + bacitracin . 


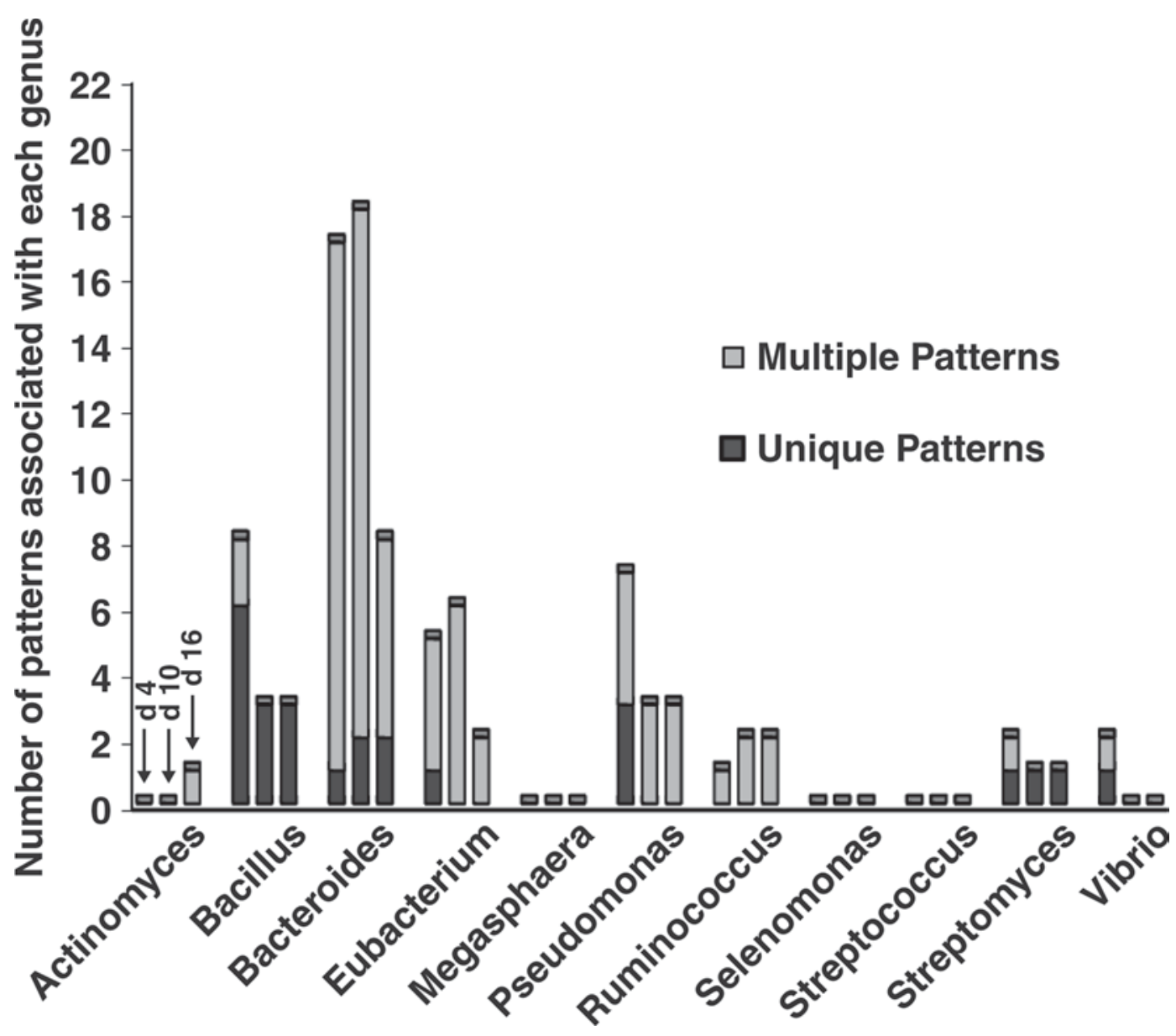

Figure 3. Patterns identified by In Silico software (In Silico LLC, Fuquay-Varina, NC) as belonging to 11 important rumen genera present in the control fermentor. Data are presented as the number of patterns detected for each genus (left bar $=\mathrm{d} 4$; middle bar $=\mathrm{d} 10$; right bar $=$ d 16).

B (612; Table 3). Similarly, the numbers of unclassified and multiple fragment patterns were reduced in cultures receiving $\mathrm{M}$ when compared with $\mathrm{B}$, $\mathrm{O}$, and the control. Fragment patterns identifying one unique species in both the Chloroflexi and Deferribacteres classes were detected in $\mathrm{M}$ but not in the control, B, or O. In contrast, fragment patterns identified as Flavobacteria or Nitrospira were detected in the latter 3 treatments, but not in M. Eleven unique patterns were classified as Actinobacteria in the control, whereas M, B, and $\mathrm{O}$ had 4, 21, and 14, respectively. The total number of Delta-proteobacteria patterns was similar in $\mathrm{O}, \mathrm{M}$, and $\mathrm{B}(10,10$, and 11, respectively), compared with the control (6).

Compared with the control, fermentors that received B had more unique fragment patterns in several classes, including Actinobacteridae, Alpha-proteobacteria, Bacilli, and Clostridia. Although $\mathrm{M}$ did not change the number of Alpha-proteobacteria or Clostridia patterns, a greater number of Bacilli patterns (7 vs. 5), as well as a lower number of Actinobacteridae patterns (2 vs. $6)$, were detected when compared with the control. With the exception of Actinobacteridae, $\mathrm{O}$ increased the number of patterns in all classes compared with the control. Compared with the control, Beta- and Gamma-proteobacteria patterns were detected in greater numbers in $\mathrm{B}$ and $\mathrm{O}$, whereas $\mathrm{M}$ had no effect. Numerically, there were fewer patterns in the Bacteroidetes class with $\mathrm{M}, \mathrm{B}$, or $\mathrm{O}$ when compared with the control (Table 3).

The $\mathrm{H}^{\prime}, 1-\mathrm{D}$, and 1/D index values were greater for $\mathrm{B}$ and $\mathrm{O}$ compared with the control, and the $\mathrm{E}$ value for O was greater and for B was lesser than for the control. (Table 4). In contrast, $\mathrm{M}$ resulted in a reduction in all 4 indices when compared with the control, B, and O. Although M had a lower index value when compared with the control, it had a greater total number of fragments for the 3 restriction digests. These data suggest that even though more fragments may be detected in a sample, the calculated diversity index of the sample 
may be lower because the fluorescence intensity of certain fragments is higher in proportion, thereby skewing the contribution of each individual fragment and lowering the calculated diversity values.

As expected, $\mathrm{M}$ and $\mathrm{O}$ decreased the $\mathrm{A}: \mathrm{P}$ ratio and methane production (Russell, 1987; Jenkins et al., 2003) when compared with the control; addition of B did not affect the $A: P$ ratio and was intermediate in its effect on methane (Russell and Strobel, 1988). In contrast, B had the greatest impact on microbial populations compared with either $\mathrm{M}$ or $\mathrm{O}$. Both $\mathrm{M}$ and $\mathrm{B}$ are known to preferentially target gram-positive microbes, where $\mathrm{M}$ disrupts cell membrane permeability and B inhibits cell wall synthesis and subsequent growth. The mechanism of action of $\mathrm{O}$ is less well known and is related to toxicity coupled with coating of substrate, in this case fiber, thereby restricting access of the fiber to microbial degradation (Siewert and Strominger, 1967). Clearly, there were differences in microbial patterns in cultures that received $\mathrm{M}, \mathrm{B}$, and $\mathrm{O}$. These differences would reflect the difference in their mode of action. However, the data also indicate that changes in microbial patterns were not reflected in the fermentation parameters.

Based on the data at the class level, M reduced and B increased microbial diversity. Although lower numbers of unique patterns were detected in the fermentors that received $\mathrm{M}$, the same fermentors also had increased numbers of unmatched fragments. This suggests that M caused preferential growth of bacteria that have not yet been studied and sequenced; therefore, they are not represented in the current pattern database.

Bacitracin treatment more than doubled the number of patterns associated with the Actinobacteria class; $\mathrm{O}$ increased the number of patterns detected by 3 , and $\mathrm{M}$ reduced the number of detected patterns by 7 . A unique fragment pattern detected in the Actinomyces genus in the B-treated fermentors partially accounts for the increase in the Actinobacteria class. In contrast, the number of detected patterns associated with the Streptomyces genus was not affected by any of the additive treatments. Therefore, other genera within the Actinobacteria class must also be responsible for some of the changes observed with $\mathrm{M}$ and $\mathrm{B}$.

The number of patterns associated with Gammaproteobacteria increased with $\mathrm{B}$ and $\mathrm{O}$ and decreased with $\mathrm{M}$. This was likely due to the change in the patterns identified in the genera Pseudomonas and Vibrio, with the latter being observed only in cultures that received $\mathrm{B}$. However, the change in patterns belonging to these 2 gram-negative genera was not sufficient to account for all of the observed increase in unique patterns. It is likely that some of the increase in Gammaproteobacteria patterns is attributable to an increase in other member organisms of the Gamma-proteobac-
Table 5. The effect of treatment (d 16) on the number of patterns associated with 11 important rumen genera ${ }^{1}$

\begin{tabular}{|c|c|c|c|}
\hline Genus & Treatment & Unique & Multiple \\
\hline \multirow[t]{4}{*}{ Actinomyces } & $\mathrm{OM}$ & 0 & 0 \\
\hline & MO & 0 & 0 \\
\hline & $\mathrm{OB}$ & 2 & 0 \\
\hline & BO & 0 & 1 \\
\hline \multirow[t]{4}{*}{ Bacillus } & $\mathrm{OM}$ & 2 & 1 \\
\hline & MO & 4 & 0 \\
\hline & $\mathrm{OB}$ & 7 & 2 \\
\hline & $\mathrm{BO}$ & 0 & 0 \\
\hline \multirow[t]{4}{*}{ Bacteroides } & $\mathrm{OM}$ & 1 & 9 \\
\hline & $\mathrm{MO}$ & 0 & 6 \\
\hline & OB & 1 & 14 \\
\hline & $\mathrm{BO}$ & 1 & 15 \\
\hline \multirow[t]{4}{*}{ Eubacterium } & $\mathrm{OM}$ & 0 & 6 \\
\hline & MO & 0 & 0 \\
\hline & OB & 1 & 5 \\
\hline & BO & 0 & 0 \\
\hline \multirow[t]{4}{*}{ Megasphaera } & $\mathrm{OM}$ & 0 & 0 \\
\hline & MO & 1 & 0 \\
\hline & $\mathrm{OB}$ & 0 & 0 \\
\hline & $\mathrm{BO}$ & 0 & 0 \\
\hline \multirow[t]{4}{*}{ Psuedomonas } & $\mathrm{OM}$ & 1 & 3 \\
\hline & MO & 0 & 0 \\
\hline & OB & 3 & 6 \\
\hline & $\mathrm{BO}$ & 0 & 1 \\
\hline \multirow[t]{4}{*}{ Ruminococcus } & $\mathrm{OM}$ & 0 & 1 \\
\hline & MO & 1 & 3 \\
\hline & OB & 0 & 2 \\
\hline & BO & 0 & 2 \\
\hline \multirow{4}{*}{ Selenomonas } & $\mathrm{OM}$ & 1 & 0 \\
\hline & MO & 0 & 0 \\
\hline & $\mathrm{OB}$ & 1 & 0 \\
\hline & BO & 0 & 0 \\
\hline \multirow[t]{4}{*}{ Streptococcus } & $\mathrm{OM}$ & 0 & 0 \\
\hline & MO & 1 & 0 \\
\hline & $\mathrm{OB}$ & 0 & 0 \\
\hline & $\mathrm{BO}$ & 0 & 0 \\
\hline \multirow[t]{4}{*}{ Streptomyces } & $\mathrm{OM}$ & 1 & 0 \\
\hline & $\mathrm{MO}$ & 0 & 0 \\
\hline & OB & 1 & 0 \\
\hline & $\mathrm{BO}$ & 0 & 0 \\
\hline \multirow[t]{4}{*}{ Vibrio } & $\mathrm{OM}$ & 1 & 0 \\
\hline & MO & 0 & 0 \\
\hline & $\mathrm{OB}$ & 0 & 0 \\
\hline & $\mathrm{BO}$ & 2 & 1 \\
\hline
\end{tabular}

${ }^{1}$ Data are presented as the number of patterns associated with only a single genus (unique) or number of patterns associated with more than one genus (multiple).

teria belonging to other genera, such as Ruminobacter. Overall, total proteobacteria accounted for a greater increase in total patterns with $\mathrm{B}$ and $\mathrm{O}$, whereas they were relatively similar between the control and M. Proteobacteria stain gram negative and are the largest and most diverse group of bacteria found in the rumen. Gram-positive bacteria are more sensitive to $\mathrm{M}$, so it is not surprising that numbers of Proteobacteria were relatively similar between $\mathrm{M}$ and the control. However, $\mathrm{B}$ resulted in a substantial increase in Proteobacteria, which is an anomaly because B also targets grampositive microbes. 


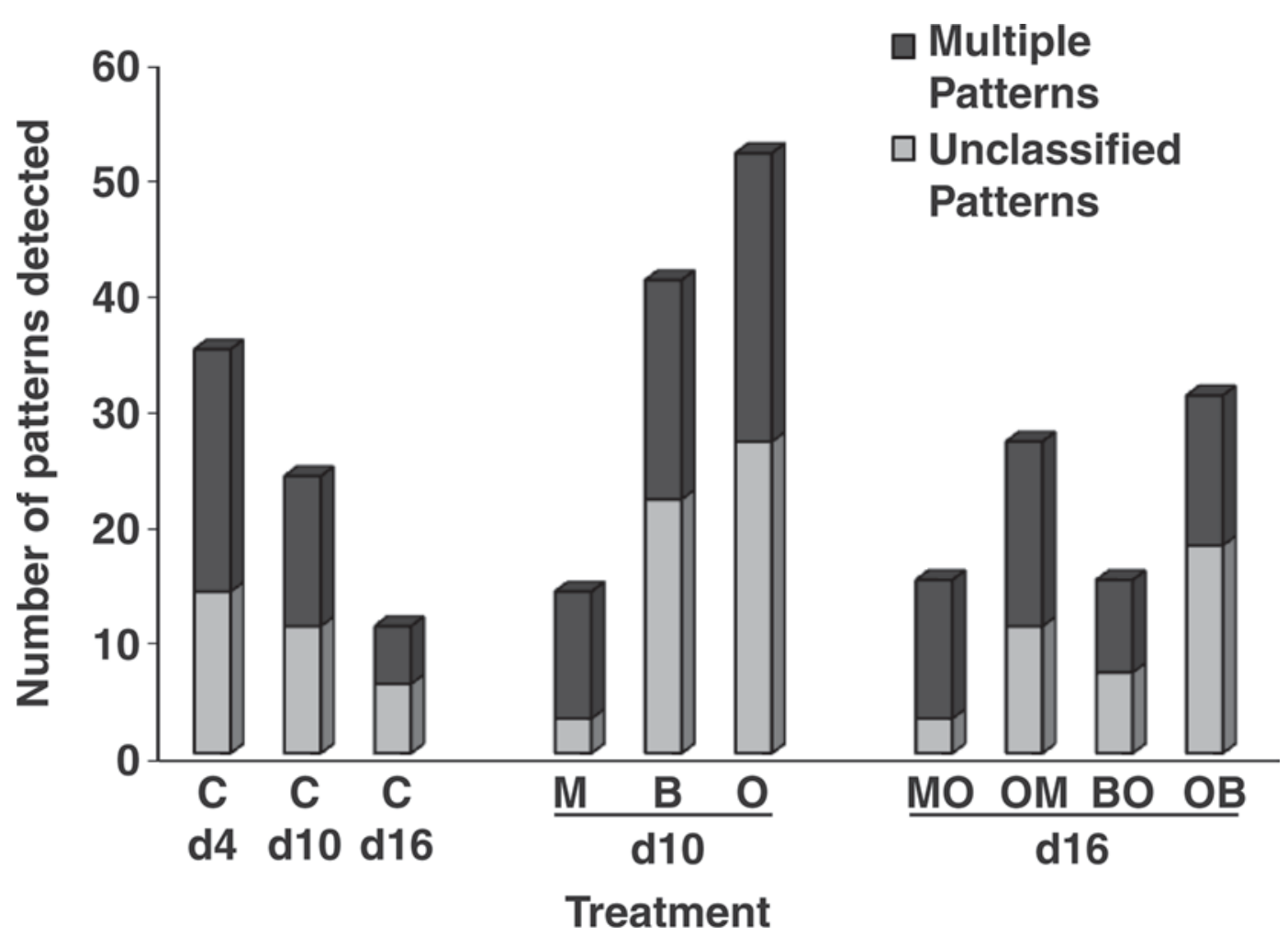

Figure 4. Effect of treatments on class patterns in the multiple and unclassified data sets having "rumen" as their origin pattern identification. $\mathrm{C}=$ control d 4, 10, and $16 ; \mathrm{M}=$ monensin; $\mathrm{B}=$ bacitracin; $\mathrm{O}=$ soybean oil; $\mathrm{MO}=$ monensin + oil; $\mathrm{OM}=$ oil + monensin; $\mathrm{BO}=$ bacitracin + oil; OB $=$ oil + bacitracin.

Although M inhibits cellulolytic species such as $R u$ minococcus, other cellulolytic organisms, such as Bacteroidetes, have been shown to increase in the presence of this ionophore (Russell, 1987; Russell and Strobel, 1989). We found that $M$ increased fragments belonging to the Bacteroides genus primarily because of an increase in Bacteroidetes patterns. Changes over time in microbial populations in the rumen have not been monitored previously by T-RFLP, and this observed increase in Bacteroides may be due to long-term selective adaptation of Bacteroides over Ruminococcus (Russell, 1987). Bacitracin did not have an effect similar to $\mathrm{M}$. For the $\mathrm{O}$ treatment, there was a decrease in the number of patterns identified that belonged to the Bacteroides genus. However, the number of patterns associated with the Bacteroidetes class was maintained at the same level as the control, suggesting that $\mathrm{O}$ affected other genera within the Bacteroidetes class.

Monensin seemed to have reduced the total number of fragments belonging to the Clostridia class when compared with the control, whereas both $\mathrm{O}$ and $\mathrm{B}$ resulted in an increase (Figure 5 and Table 3). It also seems that when $\mathrm{M}$ was added first in the sequence (MO), fewer total fragments within Clostridia were detected compared with either the control or the other additive sequences (OM, BO, and $\mathrm{OB})$. The unique patterns detected in the Selenomonas and Megasphaera genera, both of which are gram-negative organisms, do not explain the changes observed with $\mathrm{M}$. The reduced microbial diversity with $\mathrm{M}$ may have resulted in changes in species that belonged in the multiple category, which, as a proportion of the total, was greatest with $\mathrm{M}$ compared with any other treatment.

It is important to reiterate that the In Silico software reports identities based on previously deposited sequences in the NCBI database. The phylogeny associated with these sequences is used by In Silico to assign the phylogeny to the detected pattern and, if the sequence is not definitively identified at least to the genus level, it will eventually be "binned" into the unclassified category. Hence, although a large number of patterns might be assigned at a higher phylogenetic level (class, for example), that association will be lost at the finer phylogenetic levels.

\section{Effect of Treatment Sequence}

Culture pH was lower $(P<0.01)$ with OM compared with MO (Table 2). The number of unique fragment patterns for all treatment sequences is shown in Figure 




Figure 5. The effect of treatments on class patterns detected in mixed ruminal cultures. $\mathrm{C}=$ control; $\mathrm{M}=$ monensin; $\mathrm{B}=$ bacitracin; $\mathrm{O}=$ soybean oil; $\mathrm{MO}=$ monensin + oil $; \mathrm{OM}=$ oil + monensin; $\mathrm{BO}=$ bacitracin + oil; $\mathrm{OB}=$ oil + bacitracin.

5, with the numerical breakdown of each treatment presented in Table 3. At d 16, the control had a total of 125 detectable fragment patterns, MO had 88 patterns, OM had 216 patterns, BO had 197 patterns, and OB had a total of 346 patterns. The total number of unique fragment patterns detected was much lower in cultures that received the MO treatment than those that received the OM treatment (88 compared with 216). The lower number of detectable patterns in the MO treatment could be due to a lower fragment use by the In Silico database.

The OM sequence resulted in the detection of 14 unique patterns in the Gamma-proteobacteria class, which was similar to the number detected in the control; no patterns were detected in the MO sequence. The OM had 3 times the number of detectable Betaproteobacteria patterns as compared with the control (Table 3). The number of Epsilon-proteobacteria patterns decreased from 3 to 1 in the OM fermentor and to 2 detected patterns in the MO-treated fermentor. In contrast, the OM sequence resulted in a greater number of detectable patterns in Alpha-proteobacteria (2) in comparison with the control (0), whereas the MO- treated fermentor yielded one detectable pattern. The number of Bacilli patterns was 2 and 4 times greater in the $\mathrm{OM}$ and $\mathrm{MO}$ treatments, respectively, when compared with the control. Similarly, the number of detected Clostridia patterns in the control was 1, compared with 2 and 5 in $\mathrm{OM}$ and MO, respectively. The OM treatment sequence also had unique patterns in the Chloroflexi class (1 pattern) and the Sphingobacteria class (2 patterns), neither of which was present in the MO sequence.

The MO sequence had patterns unique to it in comparison with the OM sequence (1 Acidobacteria pattern and 1 Actinobacteridae pattern). Both the MO and the OM sequences had one unique fragment pattern in the Deferribacteres class, which was not detected in the control fermentor. Neither MO nor OM had fragment patterns matching the Chlorobia, Flavobacteria, Mollicutes, Nitrospira, Planctomycetacia, or Verrucomicrobiae classes.

The BO sequence had fewer total unique patterns (197) than the OB sequence (346). There were, respectively, 94 and 168 unique patterns identified as unclassified for $\mathrm{BO}$ and $\mathrm{OB}$, and 49 and 79 were identified 


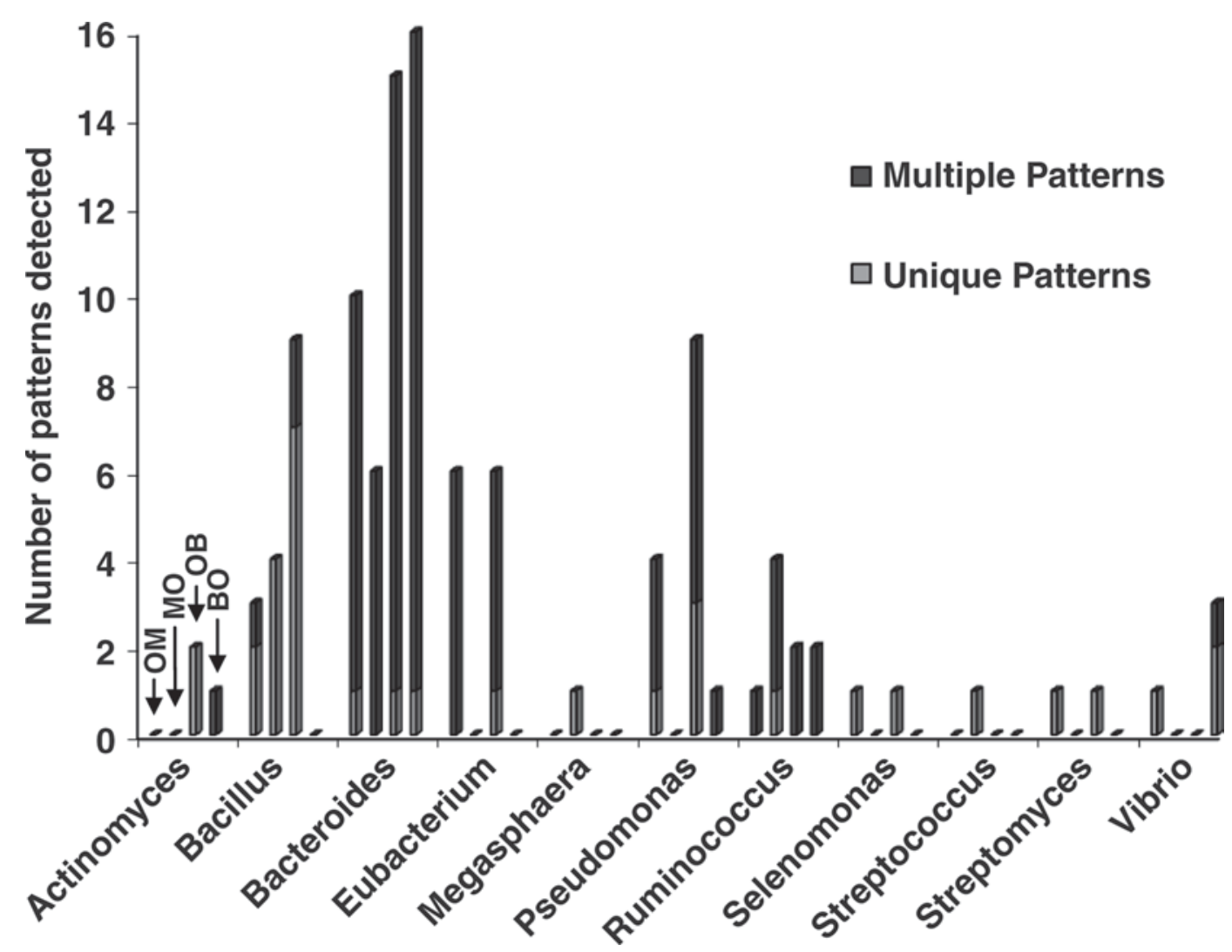

Figure 6. Effect of treatment sequence on 11 rumen genera patterns identified by In Silico software (In Silico LLC, Fuquay-Varina, NC) at d 16 in continuous mixed cultures. $\mathrm{OM}=$ oil + monensin; $\mathrm{MO}=$ monensin + oil; $\mathrm{OB}=$ oil + bacitracin; $\mathrm{BO}=$ bacitracin + oil.

as multiple. The greater number of patterns detected for $\mathrm{OB}$ is a result of both a larger number of fragments detected in the T-RFLP digests and a greater percentage of fragment utilization.

Compared with $\mathrm{OB}, \mathrm{BO}$ resulted in a greater number of patterns in the Actinobacteria and Epsilonproteobacteria classes. The number of Actinobacteria patterns detected in the $\mathrm{BO}$ sequence was 10 , compared with 8 in the $\mathrm{OB}$ sequence and 4 in the control. Greater numbers of Epsilon-proteobacteria patterns were also found in $\mathrm{BO}$, both in comparison with $\mathrm{OB}(8$ detected patterns in $\mathrm{BO}$ compared with 6 for $\mathrm{OB}$ ) and in comparison with the control (3 patterns). The BO treatment resulted in unique fragment patterns in the Acidobacteria (1), Actinobacteridae (3), Chlorobia (1), and Flavobacteria (2) classes, but none was detected in $\mathrm{OB}$.

One Acidobacteria and 3 Actinobacteridae patterns were detected for $\mathrm{BO}$ and the control, respectively (Table 3). The BO treatment had one unique Chlorobia pattern and twice as many Flavobacteria patterns compared with the control. The OB treatment resulted in a greater number of patterns for several classes. For Bacilli, the OB resulted in 12 patterns compared with 2 each for $\mathrm{BO}$ and the control. Twelve patterns were detected for Beta-proteobacteria in the OB fermentor, compared with 9 and 2 for $\mathrm{BO}$ and the control, respectively. The OB sequence resulted in 32 Gammaproteobacteria patterns, compared with 12 for $\mathrm{BO}$ and 14 for the control. Similarly, Clostridia (8 patterns), Delta-proteobacteria (7 patterns), and Mollicutes (9 patterns) were greater in the OB treatment compared with either BO or the control.

The $\mathrm{H}^{\prime}$ values were greater for $\mathrm{MO}, \mathrm{OM}, \mathrm{BO}$, and $\mathrm{OB}$ when compared with the control (Table 4). However, the $1-\mathrm{D}$ and $1 / \mathrm{D}$ values were greater in the control when compared with $\mathrm{MO}, \mathrm{OM}$, and $\mathrm{OB}$ but were lesser when compared with $\mathrm{BO}$. The $\mathrm{BO}$ treatment also had a greater $1 / \mathrm{D}$ value compared with the control. The MO, OM, and OB treatments all had lower reciprocal Simpson values of $24.213,29.416$, and 22.035 , respectively. The $\mathrm{E}$ values were less for $\mathrm{MO}, \mathrm{OM}, \mathrm{BO}$, and $\mathrm{OB}$ than for the control. However, fragment numbers were greater for all treatment sequences when compared with the control. As mentioned earlier, low values indicate that certain fragments are increasing in proportion to the rest of the fragments in the sample.

The presence of 11 rumen genera within the unique classified patterns and the multiple patterns at $\mathrm{d} 16$ are presented in Figure 6 and Table 5. As with the 
d-10 samples, multiple patterns cannot be linked to a specific identity. This classification, however, holds a large amount of diversity.

There was no change in ruminal fermentation or number of bacterial cells because of the sequence in which the ionophores and $\mathrm{O}$ were included in the diet. This is similar to results reported previously (Jenkins et al., 2003). However, we did observe changes in microbial populations despite the similarity in the fermentation pattern, and this has not been documented previously. The presence of $\mathrm{O}$ in cultures before the addition of M (OM treatment) had a substantial impact on the diversity of microbial populations; 216 patterns were detected in cultures that received the OM treatment sequence compared with only 88 for the MO treatment, which was less than when compared with the control. This could be attributed to the greater number of fragments that were not used in the In Silico analysis for the MO sequence compared with the OM sequence. In other words, the effect of $\mathrm{M}$ on rumen microbes was minimized in cultures that had already received O. Our data suggest that $\mathrm{O}$ and $\mathrm{M}$ affect different microbial populations, but this change may not be reflected in other fermentation variables such as VFA or methane. It is well known that microbes incorporate preformed fatty acids (as would be provided in $\mathrm{O}$ ) into their membranes. In fact, linoleic acid (C18:2) has been shown to be incorporated in the polar lipid fraction almost exclusively as phosphatidylcholine (Demeyer et al., 1978). Incorporation of long-chain fatty acids into cellular membranes can alter membrane polarity, increase permeability, and alter solute transfer across the cell wall. Hence, a change in membrane polarity and subsequent permeability would impede the movement of compounds such as ionophores, which require translocation across the lipid bilayer to disrupt cell function, making them less effective. This finding is further supported by the fact that trends in detectable diversity for the $\mathrm{OB}$ and $\mathrm{BO}$ sequence were different; in fact, the $\mathrm{OB}$ sequence had a higher number of detectable patterns. Furthermore, fragment use was much lower with the MO treatment sequence, suggesting that the addition of $\mathrm{M}$ before $\mathrm{O}$ increased the number of unidentifiable microorganisms in the cultures. Although gram-positive microbes have been implicated as being more sensitive to M and O (Russell and Strobel, 1988; Van Nevel and Demeyer, 1995), changes in the Gamma-proteobacteria suggest that the addition of $\mathrm{O}$ to cultures receiving M may inhibit some gram-negative organisms, because Gamma-proteobacteria were undetected in MO (i.e., cultures that received $\mathrm{O}$ after having received $\mathrm{M}$ ).

We observed a shift in microbial diversity in the control cultures across the 16-d experimental period as well as a change in diversity as a consequence of treatments.
It is worth noting that the index values reported are based on the number of fragments detected and that the values will differ because the numbers of fragments detected differ for each of the treatment conditions. It is also important to note that these values are reflective only of the fragments themselves and not of the subsequent patterns identified. Thus, the diversity values could be an underrepresentation of the true diversity, with multiple patterns being assigned to the same detected fragments (Blackwood et al., 2007). Although the diversity values are affected by the number and intensity of the fragments, they do not truly reflect the identity of the microbial population that generated the fragments.

\section{CONCLUSIONS}

Despite changes in microbial diversity, the fermentation profile in the control fermentors remained stable for extended periods. The effect of $\mathrm{M}$ and $\mathrm{O}$ on rumen fermentation was consistent with earlier reports. Bacitracin had similar effects as $\mathrm{M}$ and $\mathrm{O}$, but the magnitude of change was less. Changes in microbial populations were not always consistent with the fermentation pattern. There were major differences in microbial populations as affected by the ionophores and $\mathrm{O}$, as well as by the sequence in which they were included in the cultures. The presence of $\mathrm{O}$ in in vitro cultures altered the response to ionophores. The $\mathrm{M}$ treatment reduced microbial diversity, but not if $\mathrm{O}$ was present in the cultures. Bacitracin alone did not inhibit diversity. There was an additive effect only in cultures that received $\mathrm{B}$ before $\mathrm{O}$. The microbial community in the rumen is extremely complex. Fermentation variables may not always reflect shifts in microbial populations. Identification of rumen microbes would be a critical step to better explain the mechanisms of bacterial response to supplements and feed additives.

\section{REFERENCES}

Bauchart, D., F. Legay-Carmier, M. Doreau, and B. Gaillard. 1990. Lipid metabolism of liquid associated and solid-adherent bacteria in rumen contents of dairy cows offered lipid-supplemented diets. Br. J. Nutr. 63:563-578.

Beecher, G. R., and B. K. Whitten. 1970. Ammonia determination: Reagent modification and interfering compounds. Anal. Biochem. $36: 243-246$.

Blackwood, C. B., D. Hudleston, D. R. Zak, and J. S. Buyer. 2007. Interpreting ecological diversity indices applied to terminal restriction length polymorphism data: Insights from simulated microbial communities. Appl. Environ. Microbiol. 73:5276-5283.

Butaye, P., L. A. Devriese, and F. Haesebrouck. 2003. Antimicrobial growth promoters used in animal feed: Effects of less well known antibiotics on gram-positive bacteria. Clin. Microbiol. Rev. $16: 175-188$

Clary, E. M., R. T. Brandt Jr, D. L. Harmon, and T. G. Nagaraja. 1993. Supplemental fat and ionophores in finishing diets: Feedlot 
performance and ruminal digesta kinetics in steers. J. Anim. Sci. 71:3115-3123.

Demeyer, D. I., C. Henderson, and R. A. Prins. 1978. Relative significance of exogenous and de novo synthesized fatty acids in the formation of rumen microbial lipids in vitro. Appl. Environ. Microbiol. 35:24-31.

Edwards, J. E., N. R. McEwan, A. J. Travis, and R. J. Wallace. 2004. $16 \mathrm{~S}$ rDNA library-based analysis of ruminal bacterial diversity. Antonie Leeuwenhoek 86:263-281.

Fellner, V., F. D. Sauer, and J. K. Kramer. 1997. Effect of nigericin, monensin, and tetronasin on biohydrogenation in continuous flowthrough ruminal fermenters. J. Dairy Sci. 80:921-928.

Jenkins, T. C. 1993. Lipid metabolism in the rumen. J. Dairy Sci. $76: 3851-3863$

Jenkins, T. C., V. Fellner, and R. K. McGuffey. 2003. Monensin by fat interactions on trans fatty acids in cultures of mixed ruminal microorganisms grown in continuous fermentors fed corn or barley. J. Dairy Sci. 86:324-330.

Kent, A. D., D. J. Smith, B. J. Benson, and E. W. Triplett. 2003. Web-based phylogenetic assignment tool for analysis of terminal restriction fragment length polymorphism profiles of microbial communities. Appl. Environ. Microbiol. 69:6768-6776.

Kolber, M. A., and D. H. Haynes. 1981. Fluorescence study of the divalent cation-transport mechanism of ionophore A23187 in phospholipid membranes. Biophys. J. 36:368-391.

Kucuk, O., B. W. Hess, and D. C. Rule. 2008. Fatty acid compositions of mixed ruminal microbes isolated from sheep supplemented with soybean oil. Res. Vet. Sci. 84:215-224.

Liu, W. T., T. L. Marsh, H. Cheng, and L. J. Forney. 1997. Characterization of microbial diversity by determining terminal restriction fragment length polymorphisms of genes encoding $16 \mathrm{~S}$ rRNA. Appl. Environ. Microbiol. 63:4516-4522.

Palmquist, D. L., and T. C. Jenkins. 1980. Fat in lactation rations . J. Dairy Sci. 63:1-14. (Review)

Pressman, B. C. 1976. Biological applications of ionophores. Annu. Rev. Biochem. 45:501-530.

Rufener, W. H. Jr, W. O. Nelson, and M. J. Wolin. 1963. Maintenance of the rumen microbial population in continuous culture. Appl. Microbiol. 11:196-201.

Russell, J. B. 1987. A proposed mechanism of monensin action in inhibiting ruminal bacterial growth: Effects on ion flux and protonmotive force. J. Anim. Sci. 64:1519-1525.
Russell, J. B., and H. J. Strobel. 1988. Effect of ionophores on ruminal fermentation. Appl. Environ. Microbiol. 55:1-6.

Russell, J. B., and H. J. Strobel. 1989. Effects of additives on in vitro ruminal fermentation: A comparison of monensin and bacitracin, another gram-positive antibiotic. J. Anim. Sci. 66:552-558.

Sankaram, M. B., B. P. Shastri, and K. R. K. Easwaran. 1987 Interaction of carrier ionophores with phospholipid vesicles. Biochemistry 26:4936-4941.

Sauer, F. D., V. Fellner, R. Kinsman, J. K. Kramer, H. A. Jackson, A J. Lee, and S. Chen. 1998. Methane output and lactation response in Holstein cattle with monensin or unsaturated fat added to the diet. J. Anim. Sci. 76:906-914.

Siewert, G., and J. L. Strominger. 1967. Bacitracin: An inhibitor of the dephosphorylation of lipid pyrophosphate, an intermediate in the biosynthesis of the peptidoglycan of bacterial cell walls. Proc. Natl. Acad. Sci. USA 57:767-773.

Tajima, K., R. I. Aminov, T. Nagamine, K. Ogata, M. Nakamura H. Matsui, and Y. Benno. 1999. Rumen bacterial diversity as determined by sequence analysis of $16 \mathrm{~S}$ rDNA libraries. FEMS Microbiol. Ecol. 29:159-169.

Tajima, K., S. Arai, K. Ogata, T. Nagamine, H. Matsui, M. Nakamura, R. I. Aminov, and Y. Benno. 2000. Rumen bacterial community transition during adaptation to high-grain diet. Environ. Microbiol. 6:273-284

Thorley, C. M., M. E. Sharpe, and M. P. Bryant. 1968. Modification of the rumen bacterial flora by feeding cattle ground and pelleted roughage as determined with culture media with and without rumen fluid. J. Dairy Sci. 51:1811-1816.

Van Nevel, C., and D. I. Demeyer. 1995. Lipolysis and biohydrogenation of soybean oil in the rumen in vitro: Inhibition by antimicrobials. J. Dairy Sci. 78:2797-2806.

Ziemer, C. J., R. Sharp, M. D. Stern, M. A. Cotta, T. R. Whitehead, and D. A. Stahl. 2000. Comparison of microbial populations in model and natural rumens using $16 \mathrm{~S}$ ribosomal RNA-targeted probes. Environ. Microbiol. 2:632-643.

Zinn, R. A., and J. L. Borques. 1993. Influence of sodium bicarbonate and monensin on utilization of a fat-supplemented, high-energy growing-finishing diet by feedlot steers. J. Anim. Sci. 71:18-25. 